\title{
Surgical cancer care in the COVID-19 era: front line views and consensus
}

\section{A assistência cirúrgica oncológica na era COVID-19: opiniões e consenso do campo de batalha}

Rodrigo Nascimento Pinheiro ${ }^{1,2}$ [i]; Fellpe J.F. Coimbra 1,3; Wilson luiz da Costa-Jri,4; Heber Salvador de Castro Ribeiro 1,3; Reitan Ribeiro ${ }^{1,5}$; Alberto Julius Alves Wainstein ${ }^{1,6}$; Gustavo Andreazza laporte ${ }^{1,7}$; Manoel Jesus Pinheiro Coelho-Jr ${ }^{1,8}$; Paulo Henrique de Sousa Fernandes ${ }^{1,9}$; Eduardo Zanella Cordeiro ${ }^{1,10}$; Bruno José Queiroz Sarmento, TCBC-DF 1,2 ; Marco Antonio C Guimaraes-Filho, TCBC-RJ'1,11; Marciano Anghinoni ${ }^{1,12}$; Glauco Baiocchi ${ }^{1,13}$; AleXandre Ferreira Oliveira, TCBC-MG $1,14$.

\section{A B S T R A C T}

Objective: to suggest a script for surgical oncology assistance in COVID-19 pandemic in Brazil. Method: a narrative review and a "brainstorming" consensus were carried out after discussion with more than 350 Brazilian specialists and renowned surgeons from Portugal, France, Italy and United States of America. Results: consensus on testing for COVID-19: 1- All patients to be operated should be tested between 24 and 48 before the procedure; 2- The team that has contact with sick or symptomatic patients should be tested; 3 - Chest tomography was suggested to investigate pulmonary changes. Consensus on protection of care teams: 1 - Use of surgical masks inside the hospitals. Use of N95 masks for all professionals in the operating room; 2 - Selection of cases for minimally invasive surgery and maximum pneumoperitoneal aspiration before removal of the surgical specimen; 2 - Optimization of the number of people in teams, with a minimum number of professionals, reducing their occupational exposure, the consumption of protective equipment and the circulation of people in the hospital environment; 3 - Isolation of contaminated patients. Priority consensus: 1- Construction of service priorities; 2 - Interdisciplinary discussion on minimally invasive or conventional pathways. Conclusion: the Brazilian Society of Surgical Oncology (BSSO) suggests a script for coping with oncological treatment, remembering that the impoundment in the assistance of these cases, can configure a new wave of overload in health systems.

Keywords: Neoplasms. Public health. Pandemics. Coronavirus.

\section{INTRODUCTION}

$\mathrm{T}$ he estimate in Brazil for each year of the 2020-2022 triennium points out that there will be 625 thousand new cases of cancer (450 thousand when excluding cases of non-melanoma skin cancer). Non-melanoma skin cancer will be the most incident (177 thousand), followed by breast and prostate cancer (66 thousand each), colon and rectum (41 thousand), lung (30 thousand) and stomach (21 thousand). These data corroborate the magnitude of the problem ${ }^{1,2}$.

A few and limited studies address the risk of
COVID-19 in cancer patients undergoing treatment. The association of these diseases and its relations with our population are still poorly understood ${ }^{2}$. The operational overload of health systems in the affected countries makes the situation even more worrisome ${ }^{2-5}$, especially in areas of scarce resources. However, data are lacking to understand the dynamics of the disease and its spread in a country with peculiar characteristics like Brazil2.

From the current information, we know that cancer patients may have a higher risk of manifestations of COVID-19 disease when compared with individuals without cancer ${ }^{2,6-8}$. In addition, cancer patients have

1 - Brazilian Society of Oncological Surgery, SBCO - Rio de Janeiro - RJ - Brazil 2 - Instituto Hospital de Base do Distrito Federal, Surgery Service Oncology - Brasilia - DF - Brazil 3 - AC Camargo Cancer Center, Department of Abdominal Surgery - São Paulo - SP - Brazil 4 - Baylor College of Medicine, Department of Medicine / Epidemiology and Population Sciences - Houston - TX - United States 5 - Erasto Gaertner Hospital, Department of Oncological Surgery - Curitiba - PR - Brazil 6 - Faculty of Medical Sciences of Minas Gerais, Faculty of Medical Sciences of Minas Gerais - Belo Horizonte - MG - Brazil 7 - Santa Casa de Porto Alegre, Oncological Surgery Service - Porto Alegre - RS- Brazil 8 - Fundação Centro of Oncology Control of Amazonas - Manaus - AM- Brazil 9 - Federal University of Uberlândia, Department of Surgery - Uberlândia - MG - Brazil 10 - Oncology Research Center - CEPON- Florianópolis, Oncology Surgery - Florianópolis - SC - Brazil 11 - State University of Rio de Janeiro - UERJ, Department of Surgery - Rio de Janeiro - RJ - Brazil 12 - Hospital São Vicente, Oncology Surgery - Curitiba - PR - Brazil 13 - AC Camargo Cancer Center, Department of Gynecological Oncology - São Paulo - SP - Brazil 14 - Federal University of Juiz de Fora, Faculty of Medicine, Department of Surgery - Juiz de Fora - MG - Brazil 
had worse results in the clinical evolution of COVID-19, suggesting that more attention should be paid to this population, especially in the event of rapid deterioration of the condition ${ }^{2,6,7}$. So far, teams that have experienced this COVID-19 crisis have proposed three strategies for cancer patients $2,6,7$ :

1. Optimization of elective surgeries for cancer can be considered in endemic areas ${ }^{4}$, according to the assessment of the assistant team, conditions of care, time of crisis, and guidance from local health authorities ${ }^{2,5}$;

2. More intense measures of individual protection must be taken for cancer patients or survivors ${ }^{2,5}$;

3. Surveillance or more intensive treatment should be considered when cancer patients are infected, especially the elderly (group with higher mortality) or individuals with other serious comorbidities ${ }^{2,5,6}$.

The discussion on the postponement of cancer treatment is controversial, since the definition of severity is changeable according to the type of cancer and staging². In Brazil, there are still legal implications, with the risk of sanction of health managers, according to Law No. 12,732 / 12 (in force since 05/23/3013), which established that the first oncological treatment in SUS (Brazilian Public Health System) must begin within a maximum period of 60 days from the issuance of the pathological report ${ }^{2}$.

Current scientific evidence is incipient, so any generalized conclusions for these patients should be interpreted with caution. However, the prolonged effects induced by surgery, chemotherapy, radiotherapy and other cancer treatments, which can lead to immunosuppression, cannot be overlooked ${ }^{2,6.7}$. Due to the well-agreed need to continue the treatment of patients with severe cancer and to the imminent exhaustion of resources of all kinds and probable overloading of hospitals with patients infected with COVID-19, the Brazilian Society of Surgical Oncology (SBCO) strongly recommends the creation of COVID-19 free pathways for assisting patients with illnesses unrelated to the current epidemic, called COVID-19 free Units.

These routes must be agreed upon by local managers, both in public and private health, and must be prepared to meet the repressed demand of other units that specialize in caring for COVID-19 patients. Exceptional situations are highlighted, in which, due to an extreme emergency in public health, for a certain period the direct combat against the epidemic is required, abandoning the COVID-19 free condition. With the restoration of normality, these hospitals should also be the first to resume normal activities in view of the priority of the cases they provide care for.

Aiming also to produce knowledge, the SBCO articulated a response group, with the functions of providing surgeons with guiding information, condensed in periodic official notes, building scientific communications, and organizing the Cancer Updates event (in virtual conference format) with the participation of colleagues from countries at a more advanced stage of the pandemic.

\section{METHODS}

An international virtual event held on 03/30/2020 had the participation of more than 350 national specialists and eminent professionals in the field of surgical oncology from Milan, Italy, Porto, Portugal, Paris, France, and Seattle, USA. These professionals explained the main impressions and data from the battle front in these centers, which were in a more advanced situation of the pandemic. From this discussion resulted a summary in the form of a consensus in the style of brainstorming, and a narrative review of the literature. This text can serve as a basis for future national and international public health measures in the face of an unprecedented crisis in which little is known about the disease, its repercussions and risks for health care teams.

Meeting Objectives:

1. To understand the experiences of reference centers in different stages of the epidemic and the associated public health chaos;

2. To understand important moments of the pandemic installation;

3. To select and prioritize patients in the face of each cancer disease;

4. To organize the hospital and operating room settings; and

5. To indicate individual protection care in conventional and laparoscopic surgeries.

Testimonies:

After the appropriate presentations and introduction of the objectives, Dr. Ailton Sepúlveda, from the 
Beaujon Hospital, Paris, started the presentation by emphasizing the following points:

1. Everyone must prepare for the worst, since when least expected, chaos comes and a large number of patients will need hospital and intensive care at the same time, with a risk of resource depletion. One must prepare for the crisis, as the "wave" of infected patients is faster than the institutions' organizational capacity;

2. Dr. Sepúlveda also highlighted the scarcity of three main hospital resources, in addition to personal protective equipment:

a. Low availability of intensive care unit (ICU) beds for surgery; There is a tendency to prioritize patients with expected shorter hospitalization and ICU stay times;

b. Low availability of operating rooms, which can be used as intensive care beds;

c. Deficiency in the number of anesthesiologists, since in that country they can be designated as intensivists.

3. The side effect to cancer care is evident, the delay in definitive treatment being expected with the scarcity of the aforementioned resources.

4. The crisis is divided into five phases, and at the moment they believe they are living the second one.

a. The first is Calm before the Storm. This is the period that everyone should prepare by increasing ICU beds, respirators and other supplies;

b. The Storm: with saturated hospitals. The peak was expected to occur one week after that date;

c. Third stage, Plateau: with limitations for new patients, due to the lack of hospital resources, depending on the previous preparation instituted;

d. Improvement phase: progressive decrease in new cases and resolution of the majority of those affected;

e. The last phase, the Rebound, in which all patients who were not treated in the early stages of the pandemic will return to hospitals to treat oncological diseases.
5. He also emphasized that all French hospitals are references for COVID-19. Therefore, the space for patients with other diseases is extremely limited, and it may have been a mistake not to have hospitals for other serious diseases.

Dr. Sepúlveda pointed out that until then, patients were not tested before surgery, and that this routine would have started that same week, 24 to 48 hours before the procedures. He remembered that false negatives are around $30 \%$, and therefore, all surgical patients also undergo chest Computerized Tomography (CT) scans.

Pancreatic and liver cancer cases with few comorbidities and after neoadjuvancy are priority, and all are discussed in an interdisciplinary meeting. About liver transplants in that institution, they will be performed only in cases where the risk of death in this waiting period is greater than $50 \%$. Another problem is the lack of donors.

The cases for laparoscopy are discussed individually, always taking care to deflate the entire pneumoperitonium before removing the surgical specimen, avoiding the spray of viral particles. The use of suitable masks is mandatory.

Then, Dr. Joaquim Abreu de Sousa, from IPO, Porto, Portugal, started his testimony. He explained that Portugal is still going through a different phase, but so far the case curve is similar to the French one.

He stressed that in his institution there is an attempt to maintain a COVID-free route to protect cancer patients, but the lack of tests makes effective diagnosis difficult. In their operating room, most elective surgeries take place, but they are already decreasing, as in the case of cytoreductive surgery with HIPEC and breast surgery.

He reported that many surgeries were postponed to increase availability for priority cases, delaying procedures that could be submitted to other treatment strategies, until the end of the crisis.

Laparoscopic surgeries were suspended. There is also an attempt to reduce the duration of the procedures, since this may be related to a higher risk of team contamination. The use of telemedicine, started about three weeks before, became a reality, since it was an instrument that had not been used before.

The third to speak was Dr. Flávio Rocha, Virginia Mason Hospital, Seattle, USA. He explained that the first official case detected in the United States was in January, 
in the state of Washington, and that shortly thereafter there was a rapid and significant increase in cases. He emphasizes that the institutions prepared for the crisis from the beginning and a consistent contingency plan was implemented in a coordinated manner.

From the beginning, the physical structure was prepared to separate suspected cases from those already confirmed, with the intention of preventing contamination of non-COVID-19 patients, thus avoiding overlap. For surgical cases, they used a protocol similar to the one published by a group from Singapore ${ }^{9}$.

A major challenge, despite prior preparation, is the scarcity of personal protective equipment (PPE). There was a need for some adaptations, such as reuse of masks and equipment initially considered disposable.

A surgical committee was set up to decide on priorities and indications. It uses a system similar to the traffic lights: green, yellow and red, in an increasing sequence of priority.

Friday was set to be a day free of elective surgeries, destining this period exclusively to attend to emergency cases and other operating room demands. This blockade aims to spare the teams, as well as to optimize resources for days of greater surgical concentration, and to separate a day for decontamination of equipment, respirators and operating rooms used in the front lines.

The contamination of the health team is common, leading to a sequence of leaves and high absenteeism. This fact led to an increase in prevention of contamination of professionals who deal with the population, including the universal use of a mask inside the hospital for all patients and professionals. The recommendation is that all professionals and patients in the preoperative period be tested for the virus.

Still as a strategy to minimize the risk of COVID-19 spread among health professionals and the movement of people through the institution, about half of the residents were released from duty. At the same time, several colleges anticipated graduations, in order to accredit more professionals to practice in services across the country, and licensing them to work in any state.

In laparoscopies, the use of handports has been abolished and for each case there is a discussion on the possible risks and benefits of this access route.

The last to share the experience was Dr. Mar- cello Deraco, Institute of Tumors of Milan. He reported that practically all hospitals were dedicated to the treatment of COVID-19, except for two that remained as a reference for Oncology.

Care for cancer patients was boosted during the pandemic due to the increased risk. There is a two-level screening for all patients: First, a questionnaire is applied about symptoms, family history and previous exposure to contaminants. If the questionnaire is negative, the patient undergoes testing for COVID-19, clinical evaluation and chest tomography. Positive or suspicious cases in any of these tests result in novel exams seven days after. Patients are only operated on if they test negative twice. Another problem is the lack of tests, so only symptomatic or suspect patients are tested.

To enter the institution, hand washing, body temperature measurement and the use of surgical masks are mandatory. In the wards, everyone wears surgical masks except for otolaryngologists, thoracic surgeons and endoscopists, who use N95 masks or similar.

Due to the high demand, repairing plastic surgery, stoma closure and others without prognostic impact were suspended. Regarding laparoscopies, despite great controversy, they were suspended.

Despite all the care, cases of COVID-19 are still registered in the postoperative period. These patients are referred to a specific ward, with trained and equipped personnel. Patients not requiring surgery are transferred to another hospital. For the selection of surgical patients, the institution uses a flowchart similar to that of Seattle, using the colors green, yellow and red, as follows:

- Green: can wait > 2 months;

- Yellow: can wait from 2 weeks to 2 months;

- Red: can wait $<2$ weeks.

\section{DISCUSSION}

It is a fact that surgical procedures that can wait should thus be treated. This cited difficulty refers to another need, that of developing a standardized informed consent form (ICF), with the help of legal advice, which legally protects the assistance team and ensures the understanding and the protagonism of the patient in therapeutic decision-making. The SBCO, through the crisis-response group, whose existence is 
itself a fundamental response strategy, built this tool (ICF), composed of three parts. The first includes the identification and data of the team, the patient and the clinical case. The second part of the tool has two main functions: a session ensures that constantly updated information is delivered to the patient and with that (its second function) establishes the pedagogical character of the form. We thus inform that:

- Patients without comorbidities who undergo elective surgery may contract COVID-19 during hospitalization;

- Patients without comorbidities who undergo elective surgeries who contract COVID-19 in the postoperative period may develop more severe conditions due to the immunological changes caused by the operation;

- Patients who have contracted the infection a few days earlier may not yet have developed symptoms and mechanical ventilation during operations may result in worsening cases;

- Patients with asymptomatic infection by COVID-19 can transmit infection to the team;

- Patients who undergo elective surgery and present with respiratory complications may have symptoms similar to COVID-19 infection, causing diagnostic confusion;

- Patients who undergo elective surgeries that develop severe infection by COVID-19 in the postoperative period may have more surgical

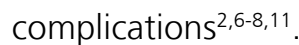

The third part of the term is the consent to carry out or to postpone the procedure after clarification.

Still in the field of knowledge as an instrument of response, the SBCO established a committee for the construction of periodic information for the press, patients, and especially for specialists, associated or not. Through this committee, they maintain contact with authorities and constituted medical entities, aiming at proactive scientific collaboration.

Understanding the set of different dynamics and situations, and evaluating the possibilities of mounting surgical oncological cases, there is a risk of another impact wave on the health system, along with the economic crisis predicted after the resolution of the pandemic. For this reason, some points regarding the institution and maintenance of COVID-19 free Oncology Hospitals (CFOH) are ${ }^{12}$ :

1. CFOHs would consume less PPE, allowing use by other hospitals;

2. CFOHs health teams would be less impacted by the pandemic and could work with less absenteeism and occupational risk;

3. Cancer patients are often immunocompromised and treatment in $\mathrm{CFOHs}$ would reduce the risk of contamination.

After the aforementioned discussion, and in view of the strategy of building knowledge and its subsequent dissemination, supporting therapeutic and management decisions, the following consensus was also established.

Consensus on testing for COVID-1912:

1. According to resources availability and determination of the local health authority, all patients to be operated on must be tested between 24 and 48 hours before the procedure;

2. Team members who have had contact with patients or who are symptomatic should be tested;

3. Routine chest tomography for surgical patients is also suggested for the investigation of pulmonary alterations, given the possibility of false negative patients even if asymptomatic. Two of the institutions (the French and Italian hospitals) perform these exams routinely.

Protection team consensus consensus ${ }^{12}$ :

1. Use of surgical masks in hospitals in view of the possibility of a significant number of asymptomatic patients and the possibility of transmission in these cases, especially in relation to the lack of little-known evidence. Use of PPE for all professionals in the operating room;

2. Careful selection of cases for minimally invasive surgery ${ }^{10,13}$ and maximum aspiration of the pneumoperitoneum before removal of the surgical specimen, avoiding "spray"12-14;

3. Optimization of teams, with a minimum number of professionals, reducing occupational exposure, consumption of protective equipment, and the circulation of people in the hospital environment; 
4. Isolation of patients in wards dedicated to caring for infected individuals if the $\mathrm{CFOH}$ cannot be installed.

Priority consensus:

1. Determination of care priorities, including those with absolute priority, in which the clinical or oncological condition may worsen within two weeks. The intermediate level can wait between two and 8 weeks. And a third one, in which waiting for more than two months should not interfere with the patient's prognosis ${ }^{12}$;

2. Discussion in meetings (preferably virtual) to assess priorities and the use of minimally invasive or conventional access routes ${ }^{10,12}$.

\section{CONCLUSION}

The SBCO herein suggests a guideline for carrying out cancer treatment, remembering that the mounting of non assisted cases may constitute a new wave of burden on health systems and that the preparation in the terms mentioned above can mitigate the announced tragedy, in particular, the mortality collaterally related to the current pandemic.

\section{Acknowledgements}

The Brazilian Society of Oncological Surgery (SBCO) thanks the renowned surgeons, Dr. Marcello Deraco, from the Tumors Institute in Milan, Ital, Dr. Joaquim Abreu de Sousa, from the Portuguese Institute of Oncology, Porto, Portugal, Dr. Ailton Sepúlveda, from Hospital Beaujon, Paris, and Dr. Flávio Rocha, Virginia Mason Hospital, Seattle, USA, for sharing the valuable contributions and experiences, at this unique moment in the history of Medicine.

\title{
R E S U M O
}

\begin{abstract}
Objetivo: sugerir roteiro de assistência oncológica cirúrgica em meio à pandemia COVID-19 no Brasil. Método: foi realizada revisão narrativa da literatura e consenso tipo "brainstorming" após discussão com mais de 350 especialistas brasileiros e cirurgiões renomados de Portugal, França, Itália e Estados Unidos da América. Resultados: consenso sobre testagem para COVID-19: 1-Todos os pacientes a serem operados devem ser testados entre 24 e 48 antes do procedimento; 2-Equipe que tenha contato com doentes ou sintomáticos deve ser testada; 3-Tomografia de tórax foi sugerida para pesquisa de alterações pulmonares. Consenso sobre proteção das equipes de assistência: 1-Uso de máscaras cirúrgicas dentro de hospitais. Uso de máscaras N95 para todos os profissionais na sala cirúrgica; 2-Seleção dos casos para cirurgia minimamente invasiva e aspiração máxima do pneumoperitônio antes da retirada da peça cirúrgica; 2-Otimização das equipes, com número mínimo de profissionais, reduzindo a exposição ocupacional, o consumo de equipamento de proteção e a circulação de pessoas no ambiente hospitalar; 3 -Isolamento de pacientes contaminados. Consenso sobre priorizações: 1-Construção de prioridades de atendimento; 2- Discussão interdisciplinar sobre via minimamente invasiva ou convencional. Conclusão: a Sociedade Brasileira de Cirurgia Oncológica (SBCO) sugere roteiro de enfrentamento para o tratamento oncológico, lembrando que o represamento na assistência desses casos, pode configurar uma nova onda de sobrecarga em sistemas de saúde.
\end{abstract}

Palavras chave: Neoplasias. Saúde Pública. Pandemias. Coronavirus. Oncologia Cirúrgica.

\section{REFERENCES}

1. INCA. Instituto Nacional de Câncer José Alencar Gomes da Silva.Estimate/2020 - Cancer Incidence in Brazil [Internet]. Rio de Janeiro: INCA; [cited 2020 May 04]; [about 1 screen]. Available from: https:// www.inca.gov.br/sites/ufu.sti.inca.local/files//media/ document//estimativa-2020-inc

2. Pinheiro RN, Oliveira AF, Ribeiro HSC, Ribeiro R, Waistein AJA, Costa Jr WL. COVID-19 and cancer surgical care in Brazil. Braz J Oncol [Internet].2020 [cited 2020 May 2];16:1-3. Available from: http:// www.brazilianjournalofoncology.com.br/details/95/ en-US/covid-19-and-surgical-cancer-care-in-brazil

3. Wu Z, McGoogan JM. Characteristics of and important lessons from the Coronavirus Disease 2019 (COVID-19) outbreak in China: summary of a report of 72314 cases from the Chinese Center for Disease Control and Prevention. JAMA. 2020 Feb 24. doi:10.1001/jama.2020.2648

4. Cascella M, Rajnik M, Cuomo A, Dulebohn SC, Di Napoli R. Features, evaluation and treatment Coronavirus (COVID-19) [Updated 2020 May 4]. In: StatPearls [Internet]. Treasure Island (FL): StatPearls 
Publishing; 2020 Jan-. Available from: https://www. ncbi.nlm.nih.gov/books/NBK554776/

5. Yang $X, Y u Y, X u J$, Shu $H, X i a ~ J, ~ L i u ~ H$, et al. Clinical course and outcomes of critically ill patients with SARS-CoV-2 pneumonia in Wuhan, China: a single-centered, retrospective, observational study. Lancet Respir Med. 2020; 8(5):475-81. [Epub ahead of print]. Erratum in: Lancet Respir Med. 2020; published online Feb 21

6. Liang W, Guan W, Chen R, Wang W, Li J, Xu K, et al. Cancer patients in SARS-CoV-2 infection: a nationwide analysis in China. Lancet Oncol. 2020;21(3):335-337. doi: 10.1016/\$14702045(20)30096-6.

7. Xia Y, Jin R, Zhao J, Li W, Shen H. Risk of COVID-19 for cancer patients. Lancet Oncol. 2020 Mar 3. pii: S1470-2045(20)30150-9. doi:10.1016/S14702045(20)30150-9.

8. Lei S, Jiang F, Su W, Chen C, Chen J, Mei W, Zhan LY, Jia Y, Zhang L, Liu D, Xia ZY, Xia Z. Clinical characteristics and outcomes of patients undergoing surgeries during the incubation period of COVID-19 infection. EClinicalMedicine. 2020 Apr 5:100331. doi: 10.1016/j.eclinm.2020.100331.

9. Ti LK, Ang LS, Foong TW, Ng BSW. What we do when a COVID-19 patient needs an operation: operating

Received in: 03/05/2020

Accepted for publication: 08/05/2020

Conflict of interest: no.

Funding source: none. room preparation and guidance. Can J Anesth. 2020. doi.org/10.1007/s12630-020-01617-4

10. Correia MITD, RamosRF, Von Bahten LC. Thesurgeons and the COVID-19 pandemic. Rev Col Bras Cir. 2020 [cited 2020 May 02] ;47: e20202536. Available from: http://www.scielo.br/scielo.php?script=sci_ arttext\&pid=S0100-69912020000100601\&lng=en . Epub Mar 30, 2020. https://doi.org/10.1590/0100$6991 \mathrm{e}-20202536$.

11. Aminian A, Safari S, Razeghian-Jahromi A, Ghorbani M, Delaney CP. COVID-19 outbreak and surgical practice: unexpected fatality in perioperative period. Ann Surg. 2020 Mar 26. doi: 10.1097/ SLA. 0000000000003925 .

12. Sociedade Brasileira de Cirurgia Oncológica. Vias Livres de COVID [Internet]. Rio de Janeiro; c2020 [cited 2020 May 1]. Available from: https://9380ed631ed3-42b2-abeb-36cdf8d20943.filesusr.com/

13. Zheng $M H$, Boni $L$, Fingerhut $A$. Minimally invasive surgery and the novel Coronavirus outbreak: lessons learned in China and Italy. Ann Surg. 2020 Mar 26. doi: 10.1097/SLA.0000000000003924.

14. American College of Surgeons [Internet]. Clinical Issues and Guidance. Available from: https://www. facs.org/covid-19/newsletter/032720/clinicalguidance

\section{Mailing address:}

Rodrigo Nascimento Pinheiro

E-mail: rodrigo@cancerdf.com.br/drnp@ig.com.br

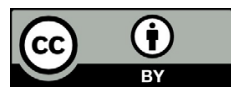

